\title{
Trait Emotion, Emotional Regulation, and Parenting Styles
}

\author{
Teresa K. Herzog ${ }^{1}$, Crystal Hill-Chapman ${ }^{1}$, Tiffany K. Hardy ${ }^{1}$, Shayna A. Wrighten ${ }^{1} \&$ Rita El-Khabbaz ${ }^{1}$ \\ ${ }^{1}$ Francis Marion University, Florence, South Carolina, United States of America \\ Correspondence: Teresa K. Herzog, Department of Psychology, Francis Marion University, PO Box 100547, \\ Florence, SC 29502-0547, USA. Tel: 1-843-661-1562. E-mail: therzog@fmarion.edu
}

Received: May 8, 2015

doi:10.5539/jedp.v5n2p119

\author{
Accepted: July 27, 2015 \\ Online Published: October 14, 2015 \\ URL: http://dx.doi.org/10.5539/jedp.v5n2p119
}

\begin{abstract}
The present study investigated relations among parenting styles and emotion regulation, trait emotion, and general well-being among 153 emerging adults. Two path models were tested, finding that parenting styles contributed to multiple pathways to emotional regulation. As expected, not only did participants who reported high levels of authoritative parenting endorse high levels of positive emotion, they also reported lower levels of emotional control and emotional self-awareness. These low levels were, in turn, associated with emotional well-being. Permissive parenting positively predicted negative emotion. Because authoritarian parenting did not directly predict trait emotion, a closer examination was conducted, showing that outcomes associated with this parenting style depended upon self-reported emotional control and trait emotion. The findings suggest that the effects of authoritarian parenting depend upon the emotional climate established in the family, a factor that may help to explain variability in outcomes for children of authoritarian parents depending upon socioeconomic status and ethnicity.
\end{abstract}

Keywords: perceived parenting, parenting styles, trait emotion, emotion regulation

\section{Introduction}

Since the establishment of emerging adulthood as a unique developmental period (Arnett, 2000), considerable research has focused on the emotional aspects of this stage. Although it is a time of significant uncertainty and instability, of differentiation from family and mastery of identity outside the family unit (Bartle-Haring \& Sabatelli, 1998), of facing adult-like pressures, and of rising instances of psychopathology, this is also a time of documented well-being (Arnett, 2007). Previous research has found that the emotional climate of the family is key to the self-reported adjustment of emerging adults (Fosco, Caruthers, \& Dishion, 2012; Hatton, Donnellan, Maysn, Feldman, Larsen-Rife, \& Conger, 2008); however, little research has addressed the contributions made by the socialization practices of parents to the relative balance of negative to positive emotion. The study presented here examines dispositional emotionality and emotion regulation as outcomes of parenting styles and links these factors to the subjective emotional experience of emerging adults and to their sense of general well-being.

That people tend to respond emotionally in a characteristically-valenced manner, reflecting the proportion of positive and negative emotion that they experience, is an important attribute with strong links to optimism, fulfillment, positive relationships, and overall well-being (Diener, Suh, Lucas, \& Smith, 1999). Trait emotion shows stability over development (Cohn, Moore, \& Campbell, 1996), and is associated with physiological profiles involving prefrontal-amygdala interactions (Goodman, Rietschel, Lo, Costanzo, \& Hatfield, 2013), frontal EEG asymmetry (Allen \& Kline, 2004), the functioning of the body's stress axis (Kalin, Shelton, \& Davidson, 2000), and the immune system (Rosenkrantz et al., 2003). In addition, numerous observations made in early childhood link positive and negative emotionality to social efficacy (Eggum et al., 2012; Eisenberg, Fabes, Guthries, \& Rieser, 2000) and child behavior problems (Lengua, 2003). Moreover, by adulthood, trait affectivity shows relations to overall psychological well-being (Crawford \& Henry, 2004; Compas, Connor-Smith, \& Jaser, 2004; Rothbart \& Posner, 2006), motivation (Slessareva \& Muraven, 2004), and physical health (Panagopoulou, Montgomery, Benos, \& Maes, 2006; Watson \& Pennebaker, 1989).

Negative and positive feelings must be managed, such that, sometimes, the dampening of negative mood is necessary and, other times, enhancing positive mood is appropriate. Thus, an affective feature related to trait 
affect is emotion regulation (Cole, Martin, \& Dennis, 2004). This ability to control the intensity of emotion, or to manipulate its valence in a goal-directed manner, is, of course influenced by trait emotion, (i.e., baseline affective predisposition) yet also shows trait-like consistency itself. Nevertheless, emotion regulation is considered a separate construct from trait affect (Lengua, 2003; Mikolajczak, Nelis, Hansenne, \& Quoidbach, 2008).

Emotion regulation depends upon multiple regulatory capacities. Emotional control involves the ability to modify one's emotional responses, emotional self-awareness consists of the self-reflective capacity to evaluate one's current emotional response, and situational emotional awareness is the sensitivity to the emotional surround which may require the implementation of particular goals or solutions. Each of these regulatory facets is necessary for flexible emotional responding, yet can be problematic if present in the extreme. As one example, although emotional control allows conformance to social norms and goal-oriented performance, it is also associated with emotional disorders involving over-rigidity and denying feelings (Greenberg \& Bolger, 2001). As another illustration, emotional awareness of self and of others, although important in the construct of emotion in intelligence, can signal failures of self-regulation. In this latter case, personal objectives may experience a diminished salience relative to the objectives of others (Salovey \& Gruell, 2005). As a final example of how the benefits of emotion regulation accrue depending upon the degree to which particular facets are implemented, deficits of emotional control and awareness are linked to narcissism whereas excesses are characteristic of anxiety and depression (Kämpfe \& Mitte, 2009).

Despite the mutual dependence of trait emotion and emotion regulation, the number of studies examining congruencies between the two is small (Lengua, 2002; Lengua, 2003; Yap, Allen, O'Shea, Di Parsia, Simmons, $\&$ Sheeber, 2011). Moreover, trait emotion is often discussed as synonymous with temperament or personality, constructs that emphasize the endogenous nature of trait emotion. However, given the interdependence of these two constructs, and because emotion regulation is well-known to be shaped by early experience (Eisenberg et al., 2003), it is not surprising that previous studies have found dispositional positive and negative emotion also to be related to early experience.

Over all developmental periods, numerous studies demonstrate interrelations between parental responding and children's emotion (Eisenberg et al., 2003; Fish, Stifter, \& Belsky, 1991; Hatton et al., 2008). Presenting one instructive finding, Yap and her colleagues (2011) showed that the ability to self-regulate in an effortful manner may be a protective factor buffering the higher likelihood of trait-negative people to develop depression. This ability moderated adolescents' greater risk of depression if their mothers were negative (i.e., disapproving, contemptuous, derogatory, or augmentative) during an interaction. Importantly, this study suggests that an inter-relationship exists between the three constructs under investigation here.

A likely aspect of early experience to associate with later emotionality is parenting styles. The construct of parenting styles focuses on broadband parent behavior, incorporating emotional elements as well as those that are regulatory. Baumrind (1971) identified four patterns of parenting styles that she based upon two aspects of parent behavior: demandingness, or control, and responsiveness, or warmth. Each of these two dimensions of parenting exerts its effect relative to the presence or absence of the other dimension. Thus, demanding parents who also support the interests of their children with warmth and acceptance, foster the qualities of self-reliance and exploration in children. Demandingness without responsiveness has been linked to higher levels of distrust and discontentment in Baumrind's original sample (Baumrind, 1989). On the other hand, responsive parents who lacked control raised children who lacked self-reliance and the confidence to explore their environment.

Many research findings support Baumrind's original hypothesis regarding specific parenting styles. For example, authoritative parenting, the simultaneous use of warmth and control, has been associated with positive outcomes in numerous studies (Driscoll, Russell, \& Crockett, 2008; Gonzalez, Holbein, \& Quilter, 2002; Weiss \& Schwarz, 1996). In addition, research tends to support her original formulation that the authoritarianism and permissiveness are less successful styles. Thus, mothers who reported using more authoritarian behaviors had three-year-olds with higher internalizing and externalizing problems (Paulussen-Hoogeboom, Stams, Hermanns, Peetsma, \& Wittenboer, 2008). Moreover, low warmth has been seen to predict higher negative emotional behavior, specifically low self-esteem, externalizing, and aggression (Jabeen, Anis-ul-Haque, \& Riaz, 2013; Miller, Cowan, Cowan, Hetherington, \& Clingempee, 1993). Additionally, permissive parenting has also been associated with greater emotional negativity and immaturity (Miller, DiIorio, \& Dudley, 2002).

Despite the utility of Baumrind's theory, subsequent research has required some amendments to her original idea. Cross-cultural research found that, among African Americans and subcultures that stress a higher collectivistic 
approach to social relations, authoritarian parenting is highly normative and related to positive child outcomes (Hoff, Laursen, \& Tardif, 2002). This has been interpreted to mean that, in parenting contexts where compliance of the child is paramount, for either societal conformance or for safety of the child, authoritarian parenting is actually more adaptive.

Questions surrounding the influence of authoritarian strategies are highlighted by findings contradictory findings for this style. One study found higher parental control was linked to greater psychological control in children (Manzeske \& Stright, 2009) while yet another found only indirect relations (Patock-Peckham \& Morgan-Lopez, 2009). This suggests that the interrelationship between parental control and children's self-control may especially involve authoritarian parenting.

Nevertheless, Baumrind observed that control un-tempered by warmth has the quality of coercion, a strategy that impedes the internalization of morés that is at the heart of socialization. Control thus acts "by focusing the child's attention on the powerful status of the parent rather than on the harmful consequences of the act the parent opposes" (Baumrind, 1989, p. 361). This is especially important since a central cognitive factor resulting from inductive discipline is a children's greater understanding of the consequences of their actions. When discipline is internalized, children achieve emotion regulation.

It is important to note that the current study relies on the self-report of college students regarding the parenting style they experienced. Self-report instruments are likely to share a strong association that reflects both substantive and method variance, as well as fail to account for divergences in different points of view (Cook \& Campbell, 1979). This view is supported by the fact that children's reports of family conflict and cohesion are only weakly correlated to their parents' reports of the same experiences (Fosco, Caruthers, \& Dishion, 2012). In terms of parenting style, parents tend to emphasize the use of both warmth and control (i.e., thus describing themselves as authoritative) while children tend to focus on one dimension or the other, identifying their parents as either authoritarian or permissive (Smetana, 1995). Given the importance of the search for identity in these years, it is possible that emerging adulthood is a time of perceptual contrasts. This is supported by the observation that achieving autonomy in emerging adulthood, the central developmental task, involves both separation from parents and agency, the ability to determine one's own life course and outcomes (Lamborn \& Groh, 2009). However, because separation is associated with emotional detachment from parents, and also low self-esteem, it is possible that young people navigate autonomy by exaggerating parental factors as agentic pushes toward independence, versus focusing holistically on the parenting that they received.

The study of perceived parenting styles must take into account individual differences of gender and age. College students in the U.S. reported a more favorable opinion of authoritative and authoritarian parenting styles than permissive styles, with girls especially emphasizing the importance of authoritative parenting (Barnhart, Raval, Jansari, \& Rava, 2013). Permissiveness in parenting may decrease with age, since at least one previous study found higher parental permissiveness and lower restrictive control among older adolescents in a study of decision making and contraception (Commendador, 2011).

Fewer studies have focused directly on the association between parenting styles and the subjective experience of emotion. Nevertheless, we have some clues about these relations from previous work. For example, McGillicuddy-De Lisi and De Lisi (2007) found that college-age students, who perceived their parents as authoritative, also reported more positive family relations as compared to those who viewed parents as authoritarian. The latter perception correlated with levels of negative emotion. In addition, children of parents utilizing an authoritarian style were reported to have lower emotional regulation (Manzeske \& Stright, 2009). That perceived parenting styles are linked to emoting also comes from the evidence that children and adolescents with problem behaviors, and thus higher negative emotion, reported significantly more parental rejection that did their non-symptomatic siblings (Yahav, 2007).

Although most of the research would support the view that characteristic positive emotion is beneficial, there is evidence that the successful adaptation to adult life involves both significant negative emotion and the experience of control. Thus, negative emotion, a common sequelea of authoritarian parenting, has been positively related to self-regulation and emotional adaptability (Eisenberg et al., 2003; Lengua, 2002; Williams, Ciarrochi, \& Heaven, 2012).

The current study asked how well perceived parenting styles predict emotion regulation and how well these two realms of behavior relate to dispositional emotion in emerging adulthood. However, before conducting these analyses, we determined whether there were any differences on parenting styles, trait emotion, or emotion regulation when comparing African American to Caucasian participants. 
As our primary analyses, we sought to test path models that would estimate the following hypotheses. In terms of demographics, we anticipated that people whose families were lower in SES would report that they received more authoritarian parenting, that women would report more authoritative parenting, and that older people would report more permissive parenting. In terms of emotion regulation, our hypotheses were that parenting styles would be related to emotion regulation. However, we were also aware that emotional control and emotional self-awareness may be problematic at high levels. If this were the case, then permissive parenting would be positively related to emotional self-awareness, due to its strong connection to anxiety, and negatively related to emotional control. In regard to trait emotionality, we expected significant paths to positive emotion from authoritative parenting. These were anticipated to parallel negative paths from permissive parenting, emotional self-control, and emotional self-awareness. In addition, we expected direct and positive paths to negative emotion from authoritarian and permissive parenting styles. As discussed above, the components of emotion regulation may be associated with both positive and negative emotion; thus, we anticipated our questions regarding these variables to be answered empirically.

\section{Method}

\subsection{Participants}

One hundred and fifty three undergraduate students ( 90 women and 63 men) participated in the research as part of a psychology laboratory course. The mean age of the students was $20.70(s . d .=4.43)$. To determine the ethnic composition of students, they completed a self-report item on a demographic questionnaire that also asked for age, gender and class standing. Fifty-one percent reported being African American $(n=79), 42 \%$ Caucasian $(n=$ $64), 4 \%$ "Blended" ethnicity $(n=6), 1 \%$ Native American $(n=2), 1 \%$ Hispanic $(n=1)$, and $1 \%$ Asian $(n=1)$.

\subsection{Procedure}

Approval for the study was given by an expedited review of the Francis Marion University Institutional Review Board for Research on Human Subjects. Students gave their written consent for participation in both the primary analyses and the post hoc analyses. The primary measures for the study were gathered in one lab session lasting approximately fifty minutes.

\subsection{Measures}

\subsubsection{Parenting Styles}

The Parental Authority Questionnaire was developed by Buri (1991) to measure perceptions of Baumrind's authoritarian, authoritative, and permissive parenting styles. Each participant evaluated his or her parent's style of parenting based on their perception of parenting. Instructions prior to completing the PAQ were for the student to answer according to the behavior of the parent who they considered their "primary parent" in terms of caregiving. All but four participants indicated that the primary caregiver was their mother. Two participants indicated that the primary parent was their father and two endorsed "Other". The rating of 30 five-point Likert scale items yields three separate and continuous subscales: permissiveness, authoritarianism, and authoritativeness. Each score ranges from 10 to 50. The higher the score, the greater the amount of that style of parenting is perceived. Buri found that authoritative parents were highest in Parental Nurturance Scale, while authoritarian parenting was inversely related to nurturance. Parental permissiveness was unrelated to nurturance. Here we report similar reliability and validity estimates to that of Buri. Reliability estimates were $r=.81$ for permissiveness, $r=.86$ for authoritarianism, $r=.78$ for authoritativeness.

\subsubsection{Trait Emotion}

The PANAS measures emotional states (Watson, Clark, \& Tellegen, 1988). Ten of the items measure positive affect; the other 10 measure negative affect. For each item, participants indicate "To what extent do you feel this way in general?" $(1=$ very slightly or not at all, 5 = extremely $)$. For ease of exposition, we reversed the scoring for the 10 negative affect items so that high scores equal low negative. The reliability of each scale was high ( $\alpha$ $=.86$ and .84 , respectively).

\subsubsection{Emotion Regulation}

The Emotional Regulation Index for Children and Adolescents (ERICA; MacDermott, Gullone, Allen, King, \& Tonge, 2010) is a 17-item index is composed of three subscales: Emotional self-awareness (e.g., When I get upset, I can get over it quickly); emotional control (e.g., I have trouble waiting for something I want); and situational awareness of emotion (e.g., When others are upset, I become sad or concerned for them). Previously, the test-retest reliability for the overall ERICA for older adolescents has been noted as .83 and the Cronbach's alpha as .75 
(MacDermott et al., 2010). We found interitem reliabilities of $\alpha=.78$ for the overall ERICA, $\alpha=.56$ for emotional self-awareness, $\alpha=.73$ for emotional self-control, and $\alpha=.66$ for situational awareness. Although the ERICA has not been validated past adolescence, sixty-seven percent of our sample was twenty years-of-age or younger. Nearly two-thirds of our sample were freshman $(n=73)$ and sophomores $(n=38)$, as compared to juniors $(n=23)$ and seniors $(n=16)$.

\subsection{Statistical Analyses}

Two path analyses were fit using AMOS with the following goals: testing the overall fit of the path models to predict positive and negative emotionality. Missing data, of which there was less than ten percent, was imputed using full, Maximum Likelihood (ML) estimation. ML imputation makes the assumption that data is missing at random (Shafer \& Graham, 2002). In order to ensure that the imputation had not biased the results, we conducted the path analyses allowing missing data from two of the study variables, emotional regulation and trait emotion (there was no missing data for parenting types), finding no difference in any of the alternative analyses form the one we report here.

We allowed the previous research to guide us in choosing the paths to fit. Paths from the demographic variables were based on information outlined above. Then, paths from each of the parenting styles to each of the emotion regulation indices were allowed given the wealth of prior research on relations between the two variables. Similarly all paths from emotion regulation components were allowed to link to the trait affect under consideration. Finally and again based on the previous research, authoritative and permissive parenting were presumed to predict positive emotion and authoritarian and permissive parenting were presumed to predict negative emotion.

\section{Results}

\subsection{Preliminary Analyses}

In order to determine whether we would see group differences between African American $(n=79)$ and Caucasian $(n=63)$ participants on the study variables, we conducted a MANOVA, which revealed no disparities between the groups, neither on the omnibus test, $F(8,133)=1.05, p=.40$, nor on the between-subjects tests. Because we saw no group differences, we conducted a series of Pearson product-moment correlations between the study variables on the entire sample (see Table 1).

Table 1. Correlations among Parenting Styles, Emotion Regulation and Trait Emotion $(\mathrm{N}=150)$.

\begin{tabular}{lcccccccc}
\hline & 1 & 2 & 3 & 4 & 5 & 6 & 7 & 8 \\
\hline 1. Authoritative PS & 1 & & & & & & & \\
2. Authoritarian PS & .04 & 1 & & & & & & \\
3. Permissive PS & $.41^{* *}$ & .15 & 1 & & & & & \\
4. Emotional Control & $-.25^{* *}$ & $-.20^{*}$ & -.11 & 1 & & & & \\
5. Emotional Self-Awareness & -.01 & $.16^{*}$ & .01 & $-.44^{* *}$ & 1 & & & \\
6. Situational Awareness of Emotion & -.15 & -.02 & -.11 & .01 & .01 & 1 & & \\
7. PANAS-X Positive Emotion & $.16^{*}$ & .12 & .07 & $-.29^{* *}$ & $.23^{* *}$ & -.06 & 1 & \\
8. PANAS-X Negative Emotion & .07 & -.13 & .10 & .14 & -.15 & .21 & -.01 & 1 \\
Mean (standard deviation) & 47.03 & 32.08 & 13.38 & 2.75 & 3.20 & 3.18 & 3.54 & 1.36 \\
& $(5.87)$ & $(5.92)$ & $(2.65)$ & $(.425)$ & $(.472)$ & $(.733)$ & $(.812)$ & $(.413)$ \\
\hline
\end{tabular}

Note. PS = Parenting style as measured by the Parental Authority Questionnaire; indicates subscales of the Emotion Regulation Index for Children and Adolescents (ERICA); PANAS-X indicates the Positive and Negative Affect Scale-X; * = significant at the .05 level and ** = significant below the .01 level. 


\subsection{Predicting Trait Emotion from Parenting Styles and Emotion Regulation}

Using AMOS/SPSS 16 software, we specified two structural models (i.e., testing observed versus latent variables), one for positive emotion and one for negative emotion. Multiple imputation was applied to account for non-response. For the purpose of this paper, we used the linear regression imputation function in AMOS. This method models missing positive and negative emotion as a linear combination of predictor variables, finds the complete case whose emotion estimate is closest to that of the current incomplete case, and takes the observed emotion from the former as the imputed emotion value for the latter. For our purposes, we created five imputed datasets. The hypothesized variable relationships were estimated by model-fitting to test the maximum likelihood of the path model and calculate the path coefficients (Arbuckle, 2006). Figures 1 and 2 show the models.

Testing the model for positive emotion (see Figure 1) yielded a significant chi square, $X^{2}(26, N=150)=175.20, p$ $<.001$. Although a significant chi square indicates that the data's fit shows some difference from the model (i.e., we showed a discrepancy between the sample covariance matrix and the implied population covariance matrix), this is to be expected from an experimental analysis. However, because the chi-square value is sensitive to factors other than fit (e.g., sample size; Byrne, 2001), we were also guided by the commonly used fit indices of the comparative fit index (i.e., CFI, a measure of complete covariation in the data) and normed fit index (i.e., NFI, which takes sample size into account), and most importantly, the root mean square error of approximation (i.e., RMSEA, which estimates expectable errors of approximation when fitting the model to the data). The fit indices, $\mathrm{CFI}=.89, \mathrm{NFI}=.87$ supported accepting the proposed model relative to the independence baseline model, which assumes no relationships in the data. The RMSEA $=.06$ was good (i.e., indices below .08 indicate tenable numbers of errors of approximation; Hu \& Bentler, 1998). Thus, we accepted the model as adequate to report the study's findings. Among the sixteen paths specified, thirteen were significant.

Testing our model for negative emotion also produced a significant chi-square, $X^{2}(26, N=150)=205.77, p<.001$ Fit indices were similar to those produced by the positive emotion model, $\mathrm{CFI}=.84, \mathrm{NFI}=.82$. Again, the RMSEA $=.068$ was recommended that we support acceptance of the model. Among the sixteen paths specified in the hypothesized model, eleven were significant (See Figure 2).

For clarity, we first discuss those findings that were observed in common for both models. The paths from our demographic variables showed both expected and unexpected relations. As expected, the path from SES to authoritarian parenting supported other research showing that higher SES parents are more likely to use inductive discipline in tandem with a more democratic style of family organization. Also, a path from gender to authoritative parenting indicated that women reported experiencing higher levels of this parenting style relative to men. Not supporting our hypotheses was a negative path from age to permissive parenting, meaning older participants reported their parent as less, rather than more, permissive in parenting style.

As anticipated, parenting styles contributed multiple significant paths to emotional regulation. In regard to our uncertainty about authoritarian parenting, we found that it was negatively related to emotional self-control, indicating that emerging adults who perceived their parenting as highly authoritarian also reported being low in control of their emotions. In addition, the perception of having been parented via an authoritarian style was positively related to emotional self-awareness.

Surprisingly, we did not support our hypothesis that high authoritative parenting would be linked to higher self-reported emotional control. Instead we found that self-reporting highly authoritative parenting was linked to also reporting low emotional control and low emotional situational awareness. 


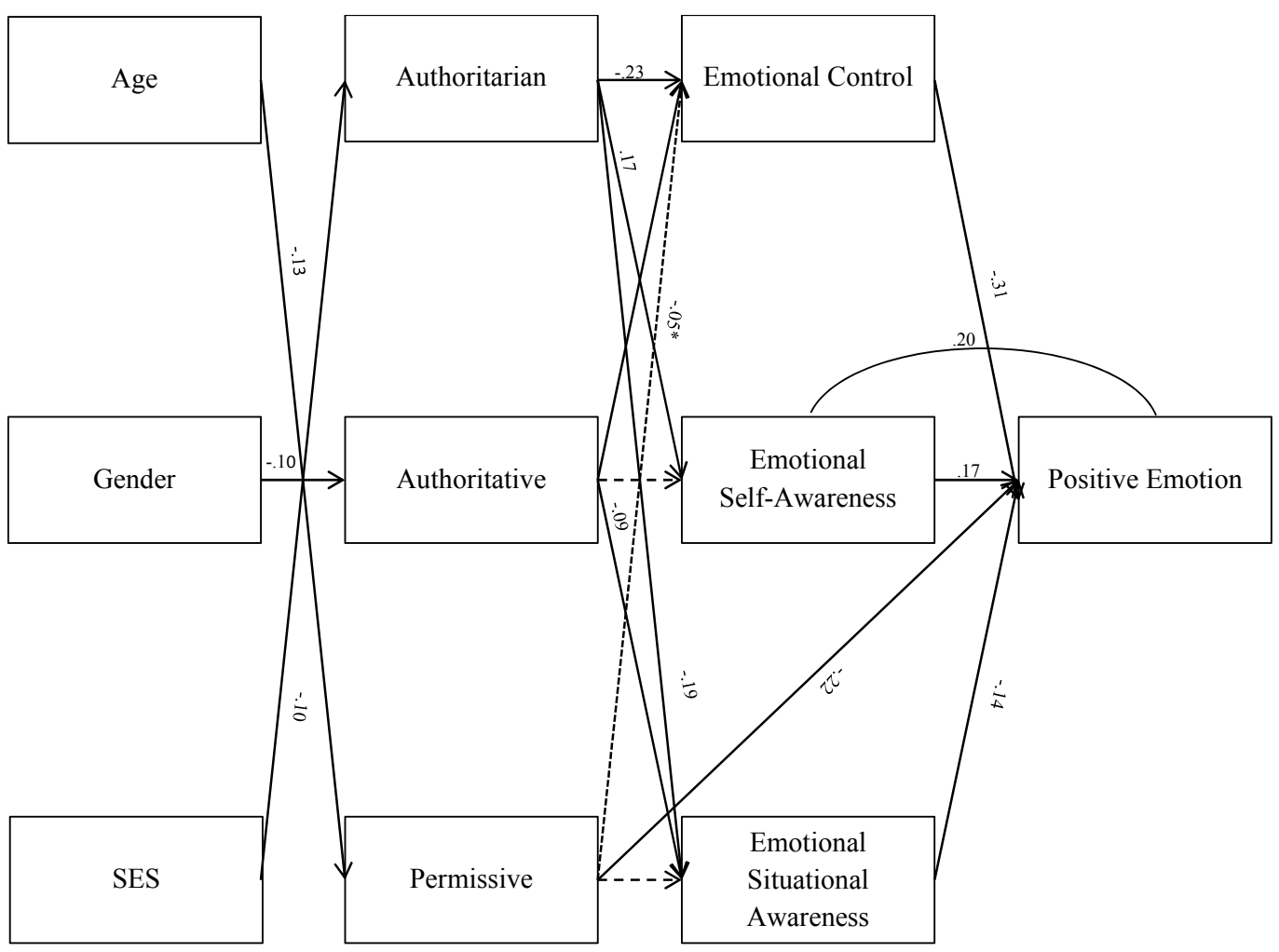

Figure 1. Path analysis to predict positive emotion $(\mathrm{N}=150)$

Notes for Model

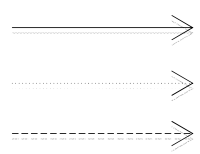

Statistically significant at $\mathrm{p}<.05$

Statistical trend towards significance

Not statistically significant 


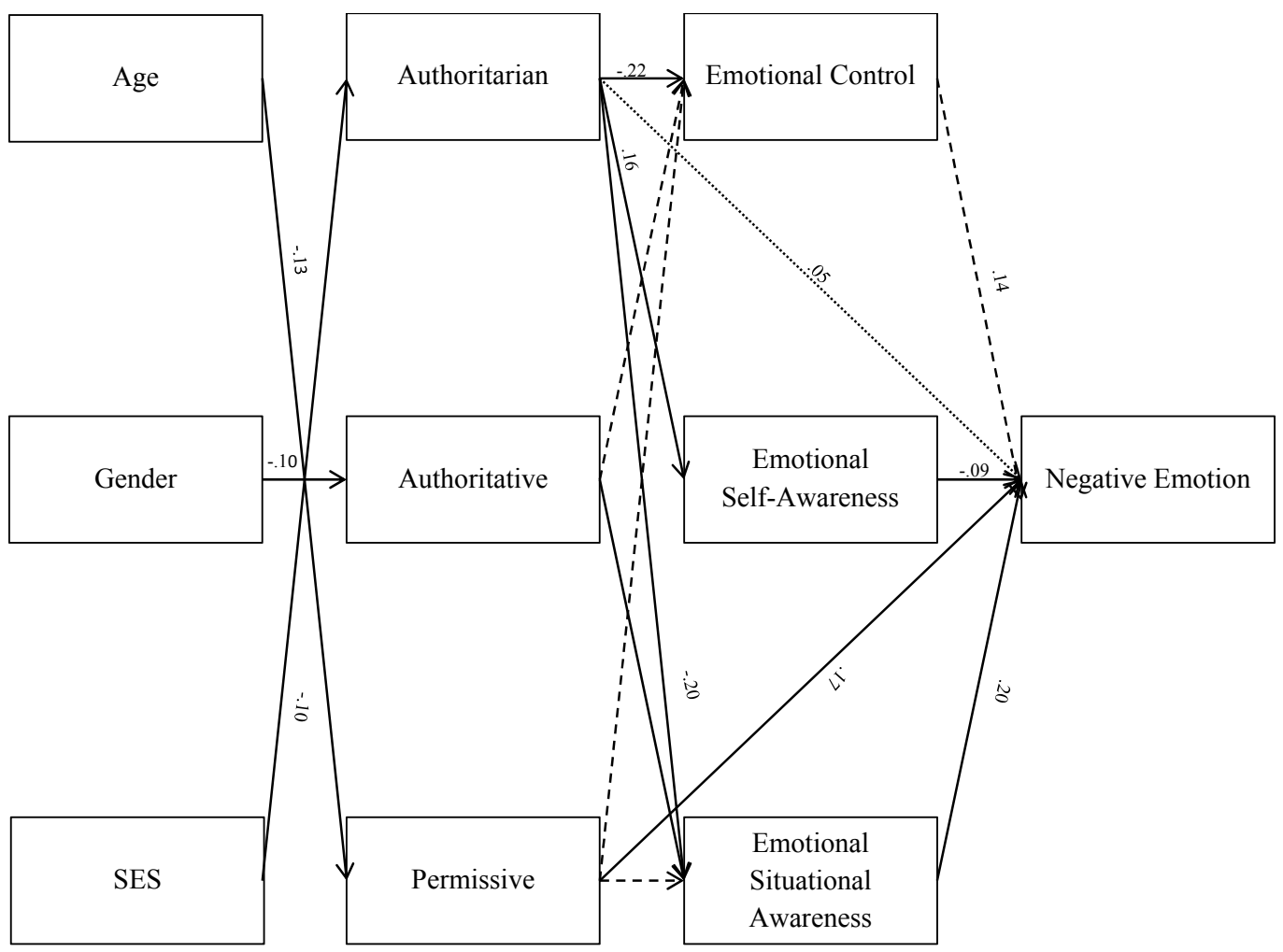

Figure 2. Path analysis to predict negative emotion $(\mathrm{N}=150)$

Notes for Model

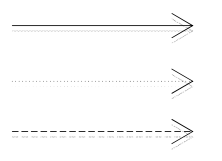
Statistically significant at $\mathrm{p}<.05$
Statistical trend towards significance
Not statistically significant

We observed a number of differences between our models. For positive emotion, we confirmed that the path from emotional situational awareness to permissive parenting was negative. This suggested that participants who reported their parent as high in permissiveness also reported themselves as low in understanding the emotional significance of social surroundings. Because there was no theoretical reason to include direct paths from authoritarian and permissive parenting to positive emotion, we allowed the effects of parenting styles to be seen through participant's emotion regulation. All three emotion regulation subscales made contributions to positive emotion, with only emotional self-awareness positively associating with positive emotion. Both paths we tested from parenting styles to positive emotion were significant in our predicted directions. Participants who reported highly authoritative parenting tended to be high in positive emotion, whereas those reporting highly permissive parenting tended to be low in positive emotion.

In the negative model, the path from emotional control to negative emotion was significant. As a mirror image of the positive model, in the negative model higher emotional self-control led to higher negative emotion. In addition, for negative emotion there were no relations between permissive parenting and emotional control. Participants high on emotional self-awareness tended to be low on negative emotion, while people high on situational awareness tended to be high on negative emotion. Finally, high emotional situational awareness predicted high levels of negative emotion. This corresponded to our idea that high situational awareness is a common component of anxiety.

In terms of predictive pathways from parenting styles, we did not support an important expectation that authoritarian parenting would predict negative emotion. Instead, we saw a strong direct link from authoritative parenting to positive emotion and an indirect link from authoritarian parenting to positive emotion via emotional self-awareness, which was itself directly linked to positive emotion. Here, those whose parents were highly 
authoritarian, and who reported having high emotional self-awareness, also tended to report high positive trait emotion. The clear contributor to high negative emotion (and also to low positive emotion) was permissive parenting. Permissive parenting predicted negative emotion. The perception of one's parent as highly permissive associated with reporting high levels of negative emotion. Thus, permissive parenting was the clearest indicator of trait negativity in our study.

We were particularly interested in ambiguities surrounding authoritarian parenting. Because our findings supported the view that authoritarian parenting was moderated by emotional regulation to predict dispositional emotion, we decided to extend this question via a post hoc analysis among the same participants, this time looking at self-reported well-being as our emotional outcome variable. In addition, we wished to verify that our measure of positive and negative motion had ecological validity in terms of psychological adjustment. A concern regarding the PANAS-X is that it does not include the term "happiness" among its items gauging positive emotion. Although Watson and Clark (1997) emphasized that the other positive items are sufficient to ensure the construct validity of the scale, we wished to verify that the use of the PANAS was indeed measuring our participants' subjective sense that their lives were characterized by well being.

\subsection{Post Hoc Analyses}

Eighty one participants in the original sample were administered a single item asking how well they experienced their life circumstances. The correlations associated with this question may be viewed in Table 2 .

Table 2. Post Hoc correlations of study variables with global life satisfaction $(\mathrm{N}=81)$

\begin{tabular}{lc}
\hline Authoritative PS & .10 \\
Authoritarian PS & .05 \\
Permissive PS & .11 \\
Emotional Control & $-.37^{* *}$ \\
Emotional Self-Awareness & $.37^{* *}$ \\
Situational Awareness of Emotion & $-.25^{*}$ \\
PANAS-X Positive Emotion & .12 \\
PANAS-X Negative Emotion & $-.35^{* *}$ \\
\hline
\end{tabular}

Note. PS = Parenting style as measured by the Parental Authority Questionnaire; indicates subscales of the Emotion Regulation Index for Children and Adolescents (ERICA); PANAS-X indicates the Positive and Negative Affect Scale-X; * = significant at the .05 level and ** = significant below the .01 level.

A multiple hierarchical regression was conducted to test how emotional socialization, emotional regulation, and dispositional emotion would predict global life satisfaction. Life satisfaction is used as a measure of convergent validity in studies of emotion regulation and positive emotion (Guzenhauzer et al., 2013) and also frequently employed as a litmus for psychological well-being (Perez \& Soto, 2011).

For this extension of our primary findings, we chose a global measure. Global perceptions differ from specific perceptions in that they are abstracted from experience over many perceptual instances (Robinson \& Clore, 2002) and are often tapped using a single item. This global measure of satisfaction with self was intended as a validation check of the findings regarding positive emotion drawn from the PANAS. We used a question drawn from the Rosenberg Self-Esteem Scale (Rosenberg, 1965), “On the whole, I am satisfied with myself”. This question is rated from 1 ("Strongly disagree") to 4 ("Strongly agree"). We entered parenting styles in Step 1, emotional regulation in Step 2, positive and negative emotion in Step 3, and, in Step 4, we entered two three-way interaction terms.

Results of the regression analyses are shown in Table 3. The direct effects revealed by the analysis suggest that participants who were high on emotional control and high on situational awareness of emotion had the lowest self-reported well-being. This finding was yet more evidence that high levels of each of these variables were subjectively experienced as negative. In order to make an estimation of the unique contribution of each predictor while controlling for the influence of the other predictors, we examined the semipartial correlations of the final 
regression equation predicting well-being. The final regression equation, where all variables are taken into account, showed that the strongest predictors of well-being were low negative emotion and low emotional control.

Table 3 Multiple hierarchical regression predicting global satisfaction from emotion socialization, emotion regulation, and characteristic emotion $(\mathrm{N}=54)$

\begin{tabular}{|c|c|c|c|c|}
\hline & $F$ & $R_{A d j}^{2}$ & $\beta$ & Semipartial \\
\hline Step 1 & 0.936 & -.004 & & \\
\hline Authoritative Parenting Style & & & .07 & -.17 \\
\hline Authoritarian Parenting Style & & & .14 & -.24 \\
\hline Permissive Parenting Style & & & .14 & .17 \\
\hline Step 2 & $4.255^{* *}$ & .160 & & \\
\hline ERICA Emotional Control & & & $-.29 *$ & -.30 \\
\hline ERICA Emotional Self-Awareness & & & -.15 & .07 \\
\hline ERICA Emotional Situational Awareness & & & $-.26^{*}$ & -.21 \\
\hline Step 3 & 1.373 & .173 & & \\
\hline PANAS - X Positive & & & -.04 & -.18 \\
\hline PANAS $-X$ Negative & & & -.23 & -.30 \\
\hline Step 4 & $3.448^{*}$ & .255 & & \\
\hline $\begin{array}{l}\text { Authoritarian } \mathrm{X} \text { Negative } \mathrm{X} \text { Emotional } \\
\text { Control }\end{array}$ & & & $.55^{*}$ & .18 \\
\hline Authoritative X Positive X Emotional Control & & & .35 & .26 \\
\hline
\end{tabular}

Note. PS = Parenting style as measured by the Parental Authority Questionnaire; indicates subscales of the Emotion Regulation Index for Children and Adolescents (ERICA); PANAS-X indicates the Positive and Negative Affect Scale-X; * = significant at the .05 level and ** = significant below the .01 level.

Over and above the direct effects of any particular variable, we verified our hypothesis that a three-way interaction between trait emotion, parenting styles, and emotional control would provide the most complete understanding of our research questions. This may be seen in Figure 3, which graphs the interaction. Participants were separated in high-low groups on the self-reported authoritarian parenting by a median split. As reflected in the figure, those participants who were low on emotional control and low on negative emotion reported the highest sense of well-being, whereas participants high on both emotional control and high on negative emotion reported the lowest well-being. In addition, authoritarian parenting reduced perceived well-being among those whose negative emotion was low. For those whose negative emotion was high, no such associations were seen. 


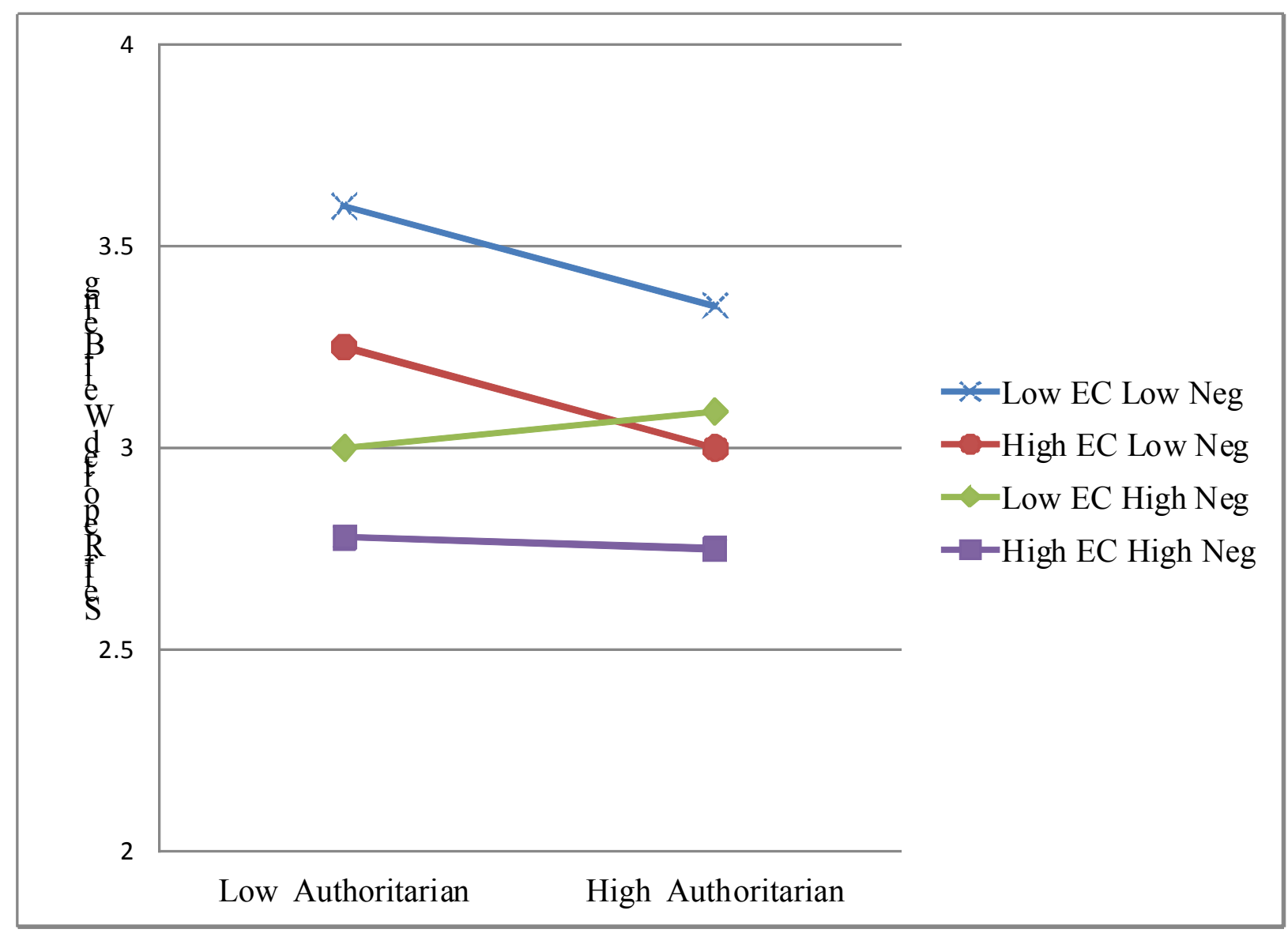

Figure 3. Three-way interaction showing relations among authoritarian parenting, emotional control, and negative emotion to predict well-being $(\mathrm{N}=81)$

\section{Discussion}

This study examined how perceived parenting styles predicted emotional regulation, and how these two behavioral factors related to dispositional emotion in emerging adulthood. The results indicated that perceived parenting styles contribute to both emotional regulation and trait emotionality. In line with numerous studies, our results support the notion that interrelations exist between these three constructs over all developmental stages (Eisenberg et al., 2003; Fish, Stifter, \& Belsky, 1991; Hatton et al., 2008). We predicted that when young adults report that their primary caregiver used an authoritative parenting style, they would also report positive emotion, while authoritarian and permissive parenting would predict high levels of negative emotion. In terms of demographics, we anticipated that gender, age, and SES would influence one's perception of parenting styles.

Demographic associations were identical for both models. Women reported higher levels of authoritative parenting styles than did men, echoing past research (Barnhart, Raval, Jansari, \& Rava, 2013), indicating that women's memories for parents' authoritative techniques were more salient. Additionally, older participants reported less permissive parenting. Because this was not predicted by previous research, future studies should determine whether this is a true age-graded effect or whether there is a tendency to "glamorize" the rigidity and control of parents over time. Because we felt it is unlikely that parenting became less restrictive for the older students in our sample relative to the younger students, we feel this finding emphasizes the appropriateness of viewing retrospective reports of parenting styles as perceived rather than actual. Finally, our participants from lower SES families reported the use of more authoritarian parenting. This is in keeping with other reports (Radziszewska, Richardson, Dent, \& Flay, 1996). However, it is important to note that recent investigations of parenting styles suggest that parental income and education do not associate identically with the dimensions of warmth and control (Anton, Jones, \& Youngstrom, 2015). 
In regard to emotion regulation, we were surprised to see that authoritative parenting and authoritarian parenting negatively predicted emotional control. Our path from permissive parenting to emotional control showed a trend toward significance in our positive model. The negative relations found here support the findings of other studies that when parents are high in permissiveness, children lack the maturity characterized by poor emotional self-control (Barton \& Kirtley, 2012). We may have failed to find a strong relationship here, because other of our findings suggest that high levels of either emotional control or emotional situational-awareness were maladaptive indicators for participants. First, they were associated with the less-than-optimal authoritarian and permissive parenting styles and second, only high levels of emotional self-awareness predicted positive emotion and low levels of negative emotion. Third, low authoritativeness predicted a high sensitivity to situational emotion and high emotional control. Emotional self-awareness was a predictor in the opposite direction: being high on this factor predicted high positive emotion and low negative emotion. On the other hand, a surprising observation was that emotional self-awareness was not predicted by authoritative parenting.

These findings suggest that emotional control and situational emotion awareness do not have linear relations with positive and negative emotion. Future research should examine whether these aspects of emotion regulation show an $\mathrm{n}$-shaped curve, with moderate amounts of these capacities reflecting a flexible and balanced access to self-containment and concern for the well-being of others. Tentatively, we take the current findings as support for our exploratory questions regarding these two variables: whether in excess, they represent, respectively, an overregulated regulatory style and anxiety.

The prediction of trait emotion by the study variables told a largely symmetrical story. Those participants high on positive emotion tended also to report authoritative parenting, high emotional self-awareness and low emotional control and emotional situational awareness. Those high on negative emotion tended to report low authoritarian parenting or high permissive parenting, low emotional self-awareness and high emotional control and emotional situational awareness.

Because both models showed that high authoritarian parenting predicted low emotional control, which in turn predicted low positive emotion and high negative emotion, we propose the tentative idea that the parental demandingness dimension goes further in providing protection against an internalizing condition of over-regulation than it does in instilling emotional self-control. Another way of interpreting this finding is that the control dimension of parenting may act to maintain "externality" is self-regulation, thus protecting against the types of internalizing control that are seen in anxiety and perfectionism.

In a similar vein, low authoritative parenting predicted high emotional situational awareness. Although additional research is needed, one possibility is that the components of authoritativeness that are not warmth or control, such as autonomy granting, create a firm foundation for an identity that is not swamped by empathic concerns of others suffering (Campbell-Sills \& Barlow, 2007).

The link between authoritative parenting and positive emotion reported here supports and adds to the findings of numerous studies indicating that the combination of control and warmth is positively correlated with higher levels of positive emotion, lower levels of behavioral problems, and overall psychological wellbeing (Driscoll, Russell, \& Crocket, 2008; Baumrind, 1991; Maccoby \& Martin, 1983). In contrast, negative emotionality was predicted by having a parent with high levels of permissiveness. This echoes other studies reporting that the children of permissive parents are low in self-control and thus tend to lack self-control and have difficulty with achievement, regulating emotions, and maturity (Baumrind, 1967; Jabeen, Haque, \& Riaz, 2013).

In addition, we produced evidence that authoritarian parenting acts to promote negative emotion through high levels of either emotional control or emotional situational awareness. A parallel was seen in the path model for positive emotion whereby low authoritarian parenting was linked to positive affect via low emotional situational awareness. Our study suggests that the commonly accepted features of emotion regulation, namely the ability to constrict one's own emotional state (i.e., emotional control) and vigilance regarding the emotions others (i.e., emotional situational awareness), can actually pose liabilities at high levels. In distinction, emotional self-awareness, the third emotion regulation variable studied here, appeared to be a robust aspect of organizing emotional behavioral strategies and experiences, associated with reductions of negative emotion and enhancement of positive emotion.

Our final analysis was a post hoc multiple hierarchical regression to further show that authoritarian parenting shows moderation effects. We demonstrated here a three-way interaction between parenting styles, trait emotionality, and emotion regulation to significantly predict global satisfaction. In this analysis, we observed that satisfaction with self occurs in the context of authoritarian parenting when emotional control and negative 
emotion are low. Future research should examine how these moderators of emotion regulation and trait affect play out in the pursuit of self-chosen environments, such as their occupational pursuits.

The findings reported here seem to underscore that, although authoritative parenting had the most direct links to positive emotional experiences, authoritarian styles do not comprise a uniformly poor approach to parenting. Rather they are situation-specific. As an example, contexts and cultures requiring social cohesion or an inordinate concern for child safety might naturally emphasize an authoritarian approach (Anton et al., 2015).

A limitation of the study is presented by our use of the ERICA. More broadly, the emotion regulation components that we relied on may have misunderstood aspects. For example, our measure was unable to discriminate between the healthy versus the pathological use of these regulating capacities. In addition, our own findings highlight the error in assuming homogeneity in child outcomes from a particular parenting style. Future studies would contribute to this discussion by identifying more fine-grained analyses within each of the styles. That being said, as shown above, our sample was comprised by statistically significantly more freshman than students of a more advanced class standing.

As discussed in the introduction, perceptions of parenting style are unlikely to represent with exact verisimilitude actual parent behaviors. A number of factors unrelated to parent behavior may be reflected in the perception. As examples, participant response style and social desirability concerns are potential threats to validity. Additionally, some people may show greater positivity bias, and some more negativity bias, although these distortions should theoretically be linked to the very factors that are measured by parenting styles. Despite these concerns, memory reliability from childhood to adulthood remains surprisingly stable (Yancura \& Aldwin, 2009).

Even as emerging adults accommodate emotionally to their increased independence, their functioning will show correspondences to perceived parent behaviors. Nevertheless, relations between parenting style and children's emotional development are complex. Future research will no doubt identify how parental control and warmth are familial technologies that modulate the use of over- and under-control in young people's emotion regulation, social functioning, and adjustment.

\section{References}

Allen, J. J. B., \& Kline, J. P. (2004). Frontal EEG asymmetry, emotion, and psychopathology: The first, and the next 25 years. Biological Psychology, 67, 1-5. http://dx.doi.org/10.1016/j.biopsycho.2004.03.001

Anton, M. T., Jones, D. J., \& Youngstrom, E. A. (2015). Socioeconomic status, parenting, and externalizing problems in African American single-mother homes: A person-oriented approach. Journal of Family Psychology, 29, 405-415. http://dx.doi.org/10.1037/fam0000086

Arbuckle, J. L. (2006). Amos 7.0. Amos Development Corporation, Spring House.

Arnett, J. J. (2000). Emerging adulthood: A theory of development from the late teens through the twenties. American Psychologist, 55, 469-480. http://dx.doi.org.10.1037/0003-066X.55.5.469

Barnhart, C. M., Raval, V. V., Jansari, A., \& Rava, P. H. (2013). Perceptions of parenting style among college students in India and the United States. Journal of Child and Family Studies, 22, 684-693. http://dx.doi.org/10.1007/s10826-012-9621-1

Bartle-Haring, S., \& Sabatelli, R. (1998). An intergenerational examination of patterns of individual and family adjustment. Journal of Marriage and Family Therapy, 60, 903-911. http://dx.doi.org/10.2307/353633

Barton, A. L., \& Kirtley, M. S. (2012). Gender differences in the relationships among parenting styles and college student mental health. Journal of American College Health, 60(1), 21-26. http://dx.doi.org/10.1080/07448481.2011.55933

Baumrind, D. (1967). Child care practices anteceding three patterns of preschool behavior. Genetic Psychology Monographs, 75, 43-88. http://dx.doi:10.1177/0272431691111004

Baumrind, D. (1989). Rearing competent children. In W. Damon (Ed.), Child development today and tomorrow (pp. 349-378). San Francisco: Jossey-Bass.

Baumrind, D. (1991). Effective parenting during the early adolescent transition. In P. S. Cowan, \& M. Hetherington (Eds.), Family Transitions, Family research consortium: Advances in family research (pp. 111-163). Hilldale, NJ: Lawrence Erlbaum.

Buri, J. R. (1991). Parental Authority Questionnaire. Personality Assessment, 57, 110-119. http://dx.doi.org/10.1207/s15327752jpa5701_13 
Byrne, B. M. (2001). Structural equation modeling with AMOS: Basic concepts, applications and programming. Mahwah, NJ: Lawrence Erlbaum Associates.

Campbell-Sills, L., \& Barlow, D. H. (2007). Incorporating emotion regulation into conceptualization and treatments of anxiety and mood disorders. In J. J. Gross (Ed.), Handbook of emotion regulation (pp. 542-559). New York: The Guilford Press.

Cohn, J. F., Moore, G. A., \& Campbell, S. B. (1996). Trait emotion and bidirectional influence in the mother-infant relationship. Infant Behavior and Development, 19, 400. http://dx.doi.org/10.1016/s0163-6383(96)90454-3

Cole, P. M., Martin, S. E., \& Dennis, T. A. (2004). Emotion regulation as a scientific construct: Methodological challenges and direction in child development research. Child Development, 75, 317-333. http://dx.doi.org/10.1111/j.1467-8624.2004.00673.x

Commendador, K. (2011). The relationship between maternal parenting style, female adolescent decision making, and contraceptive use. Journal of the American Academy of Nurse Practitioners, 23, 561-572. http://dx.doi.org/10.1111/j.1745-7599.2011.00635.x

Compas, B. E., Connor-Smith, J., \& Jaser, S. S. (2004). Temperament, stress reactivity, and coping: Implications for depression in childhood and adolescence. Journal of Clinical Child and Adolescent Psychology, 33, 21-31. http://dx.doi.org/10.1207/S15374424JCCP3301_3

Cook, T. D., \& Campbell, D. T. (1979). Quasi-experimentation design and analysis issues for field settings. Boston, MA: Houghton Mifflin.

Crawford, J. R., \& Henry, J. D. (2004). The Positive and Negative Affect Schedule (PANAS): Construct validity, measurement properties and normative data in a large non-clinical sample. British Journal of Clinical Psychology, 43, 245-265. http://dx.doi.org/10.1348/0144665031752934

Diener, E., Suh, E. M., Lucas, R. E., \& Smith, H. L. (1999). Subjective well-being: Three decades of progress. Psychological Bulletin, 125, 276-302. http://dx.doi.org/10.1037/0033-2909.125.2.276

Driscoll, A. K., Russell, S. T., \& Crockett, L. J. (2008). Parenting styles and youth well-being across immigrant generations. Journal of Family Issues, 29, 185-209. http://dx.doi.org/10.1177/0192513X07307843

Eggum, N. D., Eisenberg, N., Reiser, M., Spinrad, T. L., Valiente, C., Sallquist, J., ... Liew, J. (2012). Relations over time among children's shyness, emotionality, and internalizing problems. Social Development, 21, 109-129. http://dx.doi.org/10.1111/j.1467-9507.2011.00618.x

Eisenberg, N., Fabes, R. A., Guthrie, I. K., \& Reiser, M. (2000). Dispositional emotionality and regulation: Their role in predicting quality of social functioning. Journal of Personality and Social Psychology, 78, 136-157. http://dx.doi.org/10.1037/00223514.78.1.136

Eisenberg, N., Valienvte, C., Morris, A. S., Fabes, R. A., Cumberland, A., Reiser, M., ... Losoya, S. (2003). Longitudinal relations among parental emotional expressivity, children's regulation, and quality of $\begin{array}{lllll}\text { socioemotional functioning. } & \text { Developmental } & \text { Psychology, } & 39, & 3-19 .\end{array}$ http://dx.doi.org/10.1037/0012-1649.39.1.3

Fish, M., Stifter, C. A., \& Belsky, J. (1991). Conditions of continuity and discontinuity in infant negative emotionality: Newborn to five months. Child Development, 62, 1525-1537. http://dx.doi.org/10.1111/j.1467-8624.1991.tb01623.x

Fosco, G. M., Caruthers, A. S., \& Dishion, T. J. (2012). A six-year predictive test of adolescent family relationship quality and effortful control pathways to emerging adult social and emotional health. Journal of Family Psychology, 26, 565-575. http://dx.doi.org/10.1037/a0028873

Gonzalez, A. R., Holbein, M. F. D., \& Quilter, S. (2002). High school students' goal orientations and their relationship to perceived parenting styles. Contemporary Educational Psychology, 27, 450-470. http://dx.doi.org/10.1006/ceps.2001.1104

Goodman, R. N., Rietschel, J. C., Lo, L-C., Costanzo, M. E., \& Hatfield, B. D. (2013). Stress, emotion regulation and cognitive performance: The predictive contributions of trait and state relative frontal EEG alpha asymmetry. International Journal of Psychophysiology, 87, 115-123. http://dx.doi.org/10.1016/j.jpsycho.2012.09.008 
Greenberg, L. S., \& Bolger, E. (2001). Emotion-focused approach to the overregulation of emotion and emotional pain. Journal of Clinical Psychology/ln Session: Psychotherapy in Practice, 57, 197-211. http://dx.doi.org/10.1002/1097-4679(200102)57:2\%3C197::AID-JCLP6\%3E3.0.CO;2-O

Guzenhauzer, C., Heicamp, T., Gerbino, M., Alessandri, G., von Suchodoletz, A., Di Guinta, L., .. Trommsdorf, G. (2013). Self-efficacy in regulating positive and negative emotions: A validation study in Germany. European Journal of Psychological Assessment, 29, 197-204. http://dx.doi.org/10.1027/1015-5759/a000151

Hatton, H., Donnellan, M. B., Maysn, K., Feldman, B. J., Larsen-Rife, D., \& Conger, R. D. (2008). Family and individual difference predictors of trait aspects of negative interpersonal behaviors during emerging adulthood. Journal of Family Psychology, 22, 488-455. http://dx.doi.org/10.1037/0893-3200.22.3.448

Hoff, E., Laursen, B., \& Tardif, T. (2002). Socioeconomic status and parenting. In M. H. Bornstein (Ed.), Handbook of parenting: Vol. 2. Biology and ecology of parenting (2nd ed., pp. 231-252). Mahwah, NJ: Erlbaum.

Hu, L., \& Bentler, P. M. (1998). Fit indices in covariance structure modeling: Sensitivity to underparametized model misspecification. Psychological Methods, 3, 424-453. http://dx.doi.org/10.1037/1082-989X.3.4.424

Jabeen, F., Anis-ul-Haque, M., \& Riaz, M. N. (2013). Parenting styles as predictors of emotion regulation among adolescents. Pakistan Journal of Psychological Research, 28, 85-105.

Kalin, N. H., Shelton, S. E., \& Davidson, R. J. (2000). Cerebrospinal corticotropin-releasing hormones are elevated in monkeys with patterns of brain activity associated with fearful temperament. Biological Psychiatry, 47, 579-585. http://dx.doi.org/10.1016/S0006-3223(99)00256-5

Kämpfe, N., \& Mitte, K. (2009). What you wish is what you get? The meaning of individual variability in desired affect and affective discrepancy. Journal of Research in Personality, 43, 409-413. http://dx.doi.org/10.1016/j.jrp.2009.01.007

Lamborn, S. D., \& Groh, K. (2009). A four-part model of autonomy during emerging adulthood: Associations with adjustment. International Journal of Behavioral Development, 33, 393-401. http://dx.doi.org/10.1177/0165025409338440

Lengua, L. J. (2002). The contribution of emotionality and self-regulation to the understanding of children's response to multiple risk. Child Development, 73, 144-161. http://dx.doi.org/10.1111/1467-8624.00397

Lengua, L. J. (2003). Associations among emotionality, self-regulation, adjustment problems, and positive adjustment in middle childhood. Applied Developmental Psychology, 24, 595-618. http://dx.doi.org/10.1016/j.appdev.2003.08.002

Maccoby, E. E., \& Martin, J. A. (1983). Socialization in the context of the family: Parent-child interaction. In P. H. Mussen, \& E. M. Hetherington (Eds.), Handbook of Child Psychology: Vol. 4. Socialization, Personality, and Social Development (pp. 1-101).

MacDermott, S. T., Gullone, E., Allen, J. S., King, N. J., \& Tonge, B. (2010). The emotion regulation index for children and adolescents (ERICA): A psychometric investigation. Journal of Psychopathology and Behavioral Assessment, 32, 301-314. http://dx.doi.org/10.1007/s10862-009-9154-0

Manzeske, D. P., \& Stright, A. (2009). Parenting styles and emotional regulation: The role of behavioral and psychological control during young adulthood. Journal of Adult Development, 16, 223-229. http://dx.doi.org/10.1007/s10804-009-9068-9

McGillicuddy-De Lisi, A. V., \& De Lisi, R. (2007). Perceptions of family relations when mothers and fathers are depicted with different parenting styles. The Journal of Genetic Psychology, 16S(4), 425-442. http://dx.doi.org/10.3200/GNTP.168.4.425-442

Mikolajczak, M., Nelis, D., Hansenne, M., \& Quoidbach, J. (2008). If you can regulate sadness, you can probably regulate shame: Associations between trait emotional intelligence, emotion regulation and coping efficiency across discrete emotions. Personality and Individual Differences, 44, 1356-1368. http://dx.doi.org/10.1016/j.paid.2007.12.004

Miller, J. M., DiIorio, C., \& Dudley, W. (2002). Parenting style and adolescent's reaction to conflict: Is there a relationship? Journal of Adolescent Health, 31, 463-468. http://dx.doi.org/10.1016/S1054-139X(02)00452-4 
Miller, N. B., Cowan, P. A., Cowan, C. P., Hetherington, E. M., \& Clingempee, W. G. (1993). Externalizing in preschoolers and early adolescents: A cross-study replication of a family model. Developmental Psychology, 29, 3-18. http://dx.doi.org/10.1037/0012-1649.29.1.3

Panagopoulou, E., Montgomery, A. J., Benos, A., \& Maes, S. (2006). Are people emotionally predisposed to experience lower quality of life? The impact of negative affectivity on quality of life in patients recovering from cardiac surgery. Social Indicators Research, 76, 55-69. http://dx.doi.org/10.1007/s11205-005-4856-5

Patock-Peckham, J. A., \& Morgan-Lopez, A. A. (2009). Mediational links among parenting styles, perceptions of parental confidence, self-esteem, and depression on alcohol-related problems in emerging adulthood. Journal of Studies on Alcohol and Drugs, 70, 215-226. http://dx.doi.org/10.15288/jsad.2009.70.215

Paulussen-Hoogeboom, M. C., Stams, G. J., Hermanns, J. M., Peetsma, T. T., \& Wittenboer, G. L. (2008). Parenting style as a mediator between children's negative emotionality and problematic behavior in early childhood. The Journal of Genetic Psychology, 169(3), 209-226. http://dx.doi.org/10.3200/GNTP.169.3.09-226

Perez, C. R., \& Soto, J. A. (2011). Cognitive reappraisal in the context of oppression: Implications for psychological functioning. Emotion, 11, 675-680. http://dx.doi.org/10.1037/a0021254

Radziszewska, B., Richardson, J. L., Dent, C. W., \& Flay, B. R. (1996). Parenting style and adolescent depressive symptoms, smoking, and academic achievement: Ethnic, gender, and SES differences. Journal of Behavioral Medicine, 19, 289-305. http://dx.doi.org/10.1007/BF01857770

Robinson, M. D., \& Clore, G. L. (2002). Episodic and semantic knowledge in emotional self-report: Evidence for two judgment processes. Journal of Personality and Social Psychology, 83, 198-215. http://dx.doi.org/10/1037/0022-3514.83.1.198

Rothbart, M. K., \& Posner, M. I. (2006). Temperament, attention, and developmental psychopathology. In D. Cicchetti, \& D. J. Cohen (Eds.), Developmental psychopathology: Vol. 2. Developmental neuroscience (2nd ed., pp. 465-501). Hoboken, NJ: Wiley.

Rosenberg, M. (1965). Society and the adolescent self-image. Princeton, NJ: Princeton University Press.

Rosenkranz, M. A., Jackson, D. C., Dalton, K. M., Dolski, I., Ryff, C. D., Singer, B. H., ... Davidson, R. J. (2003). Affective style and in vivo immune response: Neurobehavioral mechanisms. Proceedings of the National Academy of Sciences of the United States of America, 100, 11148-11152. http://dx.doi.org/10.1073/pnas. 1534743100

Salovey. P., \& Grewal, D. (2005) The science of emotional intelligence. Current Directions in Psychological Science, 14, 281-285. http://dx.doi.org/10.1111/j.0963-7214.2005.00381.x

Schafer, J. L., \& Graham, J. W. (2002). Missing data: Our view of the state of the art. Psychological Methods, 7 , 147-177. http://dx.doi.org/10.1037/1082-989X.7.2.147

Slessareva, E., \& Muraven, M. (2004). Sensitivity to punishment and self-control: The mediating role of emotion. Personality and Individual Differences, 36, 307-319. http://dx.doi.org/10.1016/S0191-8869(03)00087-4

Smetana, J. (1995). Parenting styles and conceptions of parental authority during adolescence. Child Development, 66, 299-316. http://dx.doi.org/10.1111/j.1467-8624.1995.tb00872.x

Watson, D., \& Clark, L. A. (1997). Measurement and mismeasurement of mood: Recurrent and emergent issues. Journal of Personality Assessment, 68, 267-296. http://10.1207/s15327752jpa6802_4

Watson, D., Clark, L. A., \& Tellegen, A. (1988). Development and validation of brief measures of positive and negative affect: The PANAS scales. Journal of personality and social psychology, 54(6), 1063. http://dx.doi.org/10.1037/0022-3514.54.6.1063

Watson, D., \& Pennebaker, J. W. (1989). Health complaints, stress, and negative distress: Exploring the central role of negative affectivity. Psychological Review, 96, 234-254. http://dx.doi.org/10.1037/0033-295X.96.2.234

Weiss, L. H., \& Schwarz, J. C. (1996). The relationship between parenting types and older adolescents' personality, academic achievement, adjustment, and substance use. Child Development, 67, 2101-2114. http://dx.doi.org/10.1111/j.1467-8624.1996.tb01846.x 
Williams, K. E., Ciarrochi, J., \& Heaven, P. C. L. (2012). Inflexible parents, inflexible kids: A 6-year longitudinal study of parenting style and the development of psychological flexibility in adolescents. Journal of Youth and Adolescence, 41, 1053-1066. http://dx.doi.org/10.1007/s10964-012-9744-0

Yahav, R. (2007). The relationship between children's and adolescents' perceptions of parenting style and internal and external symptoms. Child: Care, Health and Development, 33, 460-471. http://dx.doi.org/10.1111/j.1365-2214.2006.00708.x

Yancura L. A., \& Aldwin, C. M. (2009). Stability and change in retrospective reports of childhood experiences over a 5-year period: Findings from the Davis Longitudinal Study. Psychology and Aging, 24, 715-721. http://dx.doi.org/10.1037/a0016203

Yap, M. B. H., Allen, N. B., O’Shea, M., Di Parsia, P., Simmons, J. G., \& Sheeber, L. (2011). Early adolescents' temperament, emotion regulation during mother-child interactions, and depressive symptomatology. Development and Psychopathology, 23, 267-282. http://dx.doi.org/10.1017/S0954579410000787

\section{Copyrights}

Copyright for this article is retained by the author(s), with first publication rights granted to the journal.

This is an open-access article distributed under the terms and conditions of the Creative Commons Attribution license (http://creativecommons.org/licenses/by/3.0/). 